The asymptotic form of the scattering amplitude for large momentum transfer given by (2) is of course a function only of $q$. As we see from (12), the result given by (1) differs from that given by (2) by polynomials in $w=2(1-\cos \theta)=q^{2} / k^{2}$, which approach unity as $k^{2} \rightarrow \infty$ for fixed $q^{2}$. For example, $\alpha 1 / q^{5}$ term in the asymptotic form of the scattering amplitude is reduced by a factor $\frac{7}{9}$ at $\theta=90^{\circ}$, and a factor $\frac{5}{9}$ at $\theta=180^{\circ}$, corrections which may be described as modest in view of the initial doubts which might have been entertained as to the relationship between (1) and (2) at large scattering angles.

* This research was supported in part by the U.S. Atomic Energy Commission.

${ }^{1}$ Sommerfeld, A., Partial Differential Equations in Physics, (New York: Academic Press, 1949) p. 279; Watson, G. N., Proc. Roy. Soc. (London), 95, 546 (1918).

\title{
EVIDENCE FOR PRELOCALIZATION OF CYTOPLASMIC FACTORS AFFECTING GENE ACTIVATION IN EARLY EMBRYOGENESIS*
}

\author{
By Eric H. Davidson, G. W. Haslett, R. J. Finney, \\ V. G. Allfrrey, ANd A. E. Mirsky \\ THE ROCKEFELLER UNIVERSTTY \\ Communicated June 14, 1965
}

Differentiation begins early in embryogenesis as different genes become active in different cells. Within the closed system of the early embryo, equal genomes thus direct the creation of diverse cell types. Though the nuclei of these cells contain complete copies of the same genome, ${ }^{1,2}$ the nucleoplasmic and cytoplasmic environments of these genomes are not the same, as a result of the distribution of cleavage nuclei into diverse areas of egg cytoplasm early in the cleavage process. In some cases the fate of these nuclei, i.e., the type of differentiated cell to which they or their descendants give rise, has been seen to depend on the area of cytoplasm in which they come to lie. For example, it was demonstrated by Hegner in 1919 that the determination of sex cells in chrysomelid beetles requires exposure of the appropriate cleavage nuclei to a clearly demarcated polar area of cytoplasm. ${ }^{3}$ Destruction of a small amount of the polar cytoplasm before it has been populated by the cleaving nuclei deprives those nuclei which normally would differentiate as sex cells of their special cytoplasmic environment. The result is the manifestation of other activities by these nuclei and their descendant lineage. Thus a complete insect is formed, but primary sexual tissue is absent. The first remarkable case of this kind is Boveri's famous 1909 demonstration of sex-cell determination in Ascaris, in which only genomes exposed to certain polar cytoplasm are protected from chromatin diminution and thus preserved for their subsequent role as sexual stem cells. ${ }^{4}$ The pressure plate experiments carried out on a wide variety of cleavage stage embryos by Driesch and many others, beginning in $1892,{ }^{1,5}{ }^{5}{ }^{6}$ suggest that qualitative cytoplasmic determination of nuclear differentiation is not confined to presumptive sexual tissue, but is common to all early cell types. In these 
experiments cleaving embryos are temporarily compressed between glass plates, causing each region of cytoplasm to be inhabited by nuclei other than those normally present there. On subsequent removal of the plates, however, the permanently "misplaced" nuclei are able to construct a normal pattern of differentiation. Studies carried out before 1900 by Conklin, ${ }^{7}$ Wilson, ${ }^{8}$ Boveri, ${ }^{9}$ Driesch, ${ }^{10,}{ }^{11}$ and many others (see ref. 12) thus suggest that egg cytoplasm may contain localized factors which differentially affect early embryonic nuclei and their genetic elements.

Classical studies more than a half-century old have in this way provided a theoretical orientation with which to approach the problem of selective gene activation in early embryogenesis. Furthermore, it is now possible to study gene activity in concrete terms by measuring the synthesis of the gene product, RNA, and to examine the proposition that egg cytoplasm contains stored substances capable of functioning directly or indirectly as selective gene activators. This paper represents a first attempt in that direction. In it we present direct evidence that removal of a physically distinct region of cytoplasm from the first-cleavage stage of a gastropod mollusk results in quantitative alteration of the level of RNA synthesis as embryogenesis proceeds to the stage of preparation for differentiation. This effect can first be identified long before the appearance of the first organ primordia, and cannot easily be interpreted as an injury result. Our findings are consistent with the idea that localized in certain cytoplasmic areas of the egg are factors which act by arousing certain genomic activities early in development.

Selection of the Gastropod Ilyanassa Obsoleta as Suitable Experimental Material.Elegant and informative studies published by Wilson, ${ }^{13},{ }^{14}$ Crampton, ${ }^{15}$ and Conk$\operatorname{lin}^{16}$ in the first decade of the 20 th century have made available a highly desirable embryological system for investigating such hypotheses. These studies concerned the spiralian mollusks Dentalium, Patella, Ilyanassa, and Crepidula. For Crepidula the complete cell lineage was elucidated by Conklin. ${ }^{16}$ Some of the results of these studies can be summarized as follows. (a) From its moment of origin each blastomere possesses practically the same morphogenetic potential if it and its descendants are reared in isolation as is observed for the same cell lineage in the context of the rest of the embryo. (b) The specific type of differentiation to which each blastomere lineage gives rise depends on the particular region of egg cytoplasm inherited by each given blastomere. (c) Morphogenetically significant areas of egg cytoplasm are distributed in a highly asymmetric fashion in these organisms. This is a result of cytoplasmic movements occurring after fertilization, in the course of which egg substances stored from the time of oögenesis are asymmetrically localized. (d) In Dentalium and Ilyanassa a region of egg cytoplasm known as the "polar lobe" is transiently extruded as a spherical lobe several times during maturation and early cleavage divisionst If this lobe removed, the embryo continues to develop but turns out to lack certain characteristic tissues. The tissues affected include those for which the lineage of the cell normally incorporating polar lobe cytoplasm is responsible (the "D quadrant" lineage). Thus, stored exclusively in polar lobe cytoplasm are substances needed for normal activation of the D quadrant cells inheriting this cytoplasm. Removal of the polar lobe is relatively easy; the result is an embryo containing the same genomes as a normal embryo, since the lobe contains only cytoplasm. From our point of view an or- 
ganism such as this indeed seems "expressly made for the study of development," as was remarked by Lacaze-Duthiers, who described the development of Dentalium as long ago as 18:57. ${ }^{17}$

Recent experiments of Clement ${ }^{18-20}$ have amplified the classical studies of Wilson and Crampton. Clement has shown that the polar lobe of the snail Ilyanassa contains cytoplasmic factors necessary for the production of intestine, heart, shell gland, and major mesodermal derivatives responsible for later structural organization. The cytoplasmic factors responsible are shunted to certain known cells of the $\mathrm{D}$ quadrant as these are formed in midcleavage, thereby endowing them with exclusive morphogenetic potentialities. Lobeless embryos remain healthy, however, and go on to become free-swimming motile forms, containing muscle tissue, velar cilia, enteron, stomodeum, and digestive-gland tissue. Organ differentiation is well under way by the fourth day of development, and from this time on, the

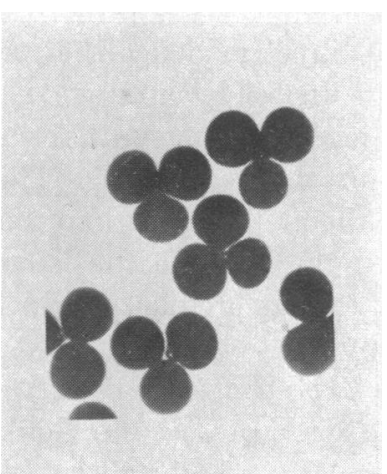

FIG. 1.-Typical Ilyanassa "trefoil." At this stage of first cleavage the cytoplasmic polar lobe can be removed, as described in Methods, leaving the $A B$ and $C D$ cells. The embryos remain in maximum trefoil for only a few minutes at $25^{\circ} \mathrm{C}$. rate of bulk RNA accumulation is about the same in normal as in lobeless embryos, according to data of Collier. ${ }^{21}$

Methods.-Ilyanassa obsoleta were secured from The Marine Biological Laboratory, Woods Hole, Massachusetts, and maintained under breeding conditions in aerated sea water. Eggs are deposited fertilized, in translucent capsules, 60-200 approximately synchronous eggs per capsule. In comparisons of lobeless and normal embryos, capsules containing uncleaved eggs were opened and the eggs were allowed to develop to the early trefoil stage of first cleavage, in filtered, pasteurized sea water containing $50 \mathrm{mg} /$ liter sulfadiazine (SSW). Figure 1 shows a living trefoil at the stage when delobing is performed. At this stage, following the method of Collier, ${ }^{22}$ they are removed to van't Hoff's calcium-free sea water, also containing sulfadiazine, and the polar lobe is removed by pipetting the embryos against the bottom of the dish. Lobeless and control embryos are then allowed to develop in SSW, at $18^{\circ} \mathrm{C}$.

Assay of RNA synthesis: To measure RNA synthesis the embryos were exposed to SSW containing uridine-5- $\mathrm{H}^{3}(17-22$ $\mathrm{c} / \mathrm{mM} ; \quad 0.5 \mathrm{mc} / \mathrm{ml})$ or uridine- $6-\mathrm{H}^{3}(3-7 \mathrm{c} / \mathrm{mM} ; 0.5 \mathrm{mc} / \mathrm{ml})$. The labeled embryos were then washed with SSW three times and frozen in SSW. They were next thawed and homogenized with a motor-driven spinning glass rod, $200 \mu \mathrm{g}$ bovine gamma globulin were added to each 1-cc tube, and PCA was added to a final concentration of $0.2 \mathrm{~N}$. The tubes were centrifuged, and the acid-soluble supernatants removed. Precipitates were washed two more times in $0.2 \mathrm{~N}$ PCA using motor-driven fine glass rods for stirring, and drawn-out fine glass pipettes for removal of the supernatants. The precipitates were washed in 3:1 alcohol-ether and $100 \%$ alcohol and dried in a stream of air. They were then incubated for $3 \mathrm{hr}$ at $37^{\circ} \mathrm{C}$ with 0.1 cc per tube of $0.20 \%$ Worthington $3 \times$ crystallized pancreatic RNase in $0.01 M \mathrm{pH} 7.6$ tris- $\mathrm{HCl}$ buffer-0.14 $M$ NaCl. The solution was then chilled, brought to a final concentration of $0.20 \mathrm{~N} \mathrm{PCA}$, and centrifuged. An aliquot of the acid-soluble supernatant was counted in a scintillation spectrometer. To measure counts which were resistant to $\mathrm{RNase}$, the precipitate was re-extracted with $0.5 \mathrm{~N} \mathrm{PCA}$ at $70^{\circ}$ for $20 \mathrm{~min}$, and the solubilized radioactivity assayed. Only a negligible proportion of the counts was recovered in this fraction.

Cytological procedures: Cell counts were periormed by the squash method. Embryos to be used for radioautography were incubated with uridine $-\mathrm{H}^{3}$ as above, fixed in osmium tetroxide, dehydrated in an alcohol series, and embedded in epon. One- $\mu$ sections were cut, and were overlaid with Kodak AR-10 stripping film. Actinomycin was used at $100 \mu \mathrm{g} / \mathrm{ml}$.

Validity of the method for RNA synthesis: Since only $4 \times 10^{-3} \mu \mathrm{g}$ RNA is present per embryo, ${ }^{23}$ 
and since it is difficult to obtain very large numbers of lobeless embryos within a short time, a method for measuring uptake of RNA precursor into a very small number of embryos is needed. Such a method permits a single group of lobeless embryos to be compared to their controls at several points in time following delobing. We have found that the use of high-specific-activity tritiated uridine combined with RNase extraction of the incorporated counts from the cold acid-insoluble residue makes possible the reproducible assay of RNA synthesis in as few as 10 embryos per tube. In our hands this method was superior to adaptations of the PCA extraction or alkaline hydrolysis methods. Figure 2 shows that RNasereleased counts are proportional to the number of embryos assayed.

Results.-RNA synthesis by lobeless and normal embryos: In Figure 3 is presented the results of three separate experiments describing RNA synthesis in 2$\mathrm{hr}$ pulses by matched normal and lobeless Ilyanassa embryos. The results of a larger number of similar experiments are summarized in Table 1. Though the details are not precisely the same from one experiment to another, the main results are clear. At

first no quantitative difference in the RNA synthesis of lobeless and normal embryos can be detected, but as development proceeds and the level of gene activity rises, the normal embryos display significantly more activity than do the lobeless embryos.

During the initial period $0-6 \mathrm{hr}$ after trefoil (i.e., $9-10 \mathrm{hr}$ of development) the

FIG. 3.- Three experiments in which lobeless and normal embryos are compared. Uridine- $\mathrm{H}^{3}$ uptake into the RNA of the embryos during a 2-hr labeling period is plotted against the number of hours which have elapsed between trefoil, when delobing is performed, and the time of labeling. Trefoil occurs about $3.5 \mathrm{hr}$ after the eggs are shed. Each point represents the average of triplicate (expts. $I$ and $I I$ ) or quadruplicate (expt. III) determinations for each class of embryo. The brackets give the absolute range of the values recorded. Each tube contained 15 embryos. To obtain comparisons between normal and lobeless embryos, two methods were followed: (a) lobeless embryos from several capsules of eggs
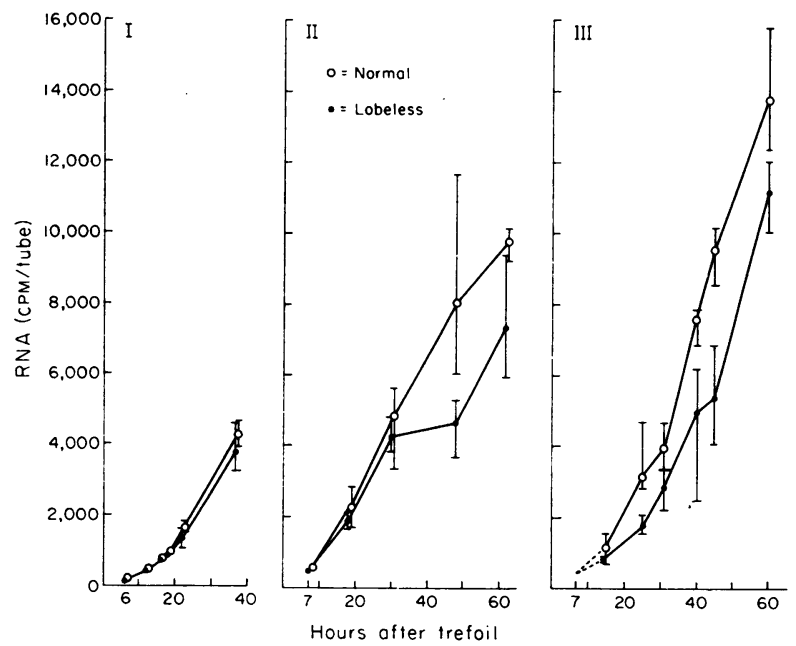

were matched to embryos from

other capsules which had been arrested in the trefoil stage by cold treatment. At the completion of the delobing process, the cold-arrested trefoils were released and immediately resumed normal development. (b) Each capsule of eggs used was split, some of the trefoils serving as controls, and others being used for delobing. When embryos from more than one capsule were pooled, each capsule was made to contribute to the pooled group a number of controls equal to the number of lobeless embryos obtained from that capsule. Thus the proportional representation of any given capsule was the same in the lobeless as in the control group. The results obtained, however, showed that method $(a)$ gives exactly the same results as method $(b)$. 
rate of RNA synthesis remains virtually identical in lobeless and normal embryos. This period includes the formation of the first "D quadrant" derivatives whose descendants will possess special morphogenetic significance. Gene activity begins very early in cleavage, and increases continuously as cleavage progresses. This is shown by the data of Figure 3 and by radioautographic studies. The latter also demonstrate the actinomycin sensitivity of nuclear uridine incorporation into RNA. Despite the occurrence of gene activity and of progressive gene activation during this phase, the morphological events taking place at this time are able to continue in the presence of actinomycin. ${ }^{21}$ In this the Ilyanassa embryo is similar to sea urchin, ascidian, and amphibian embryos, which satisfactorily complete cleavage in the presence of actinomycin, ${ }^{24-26}$ or even in the total absence of a nucleus. ${ }^{27}$ Absence of polar lobe cytoplasm does not appear to affect gene activation in these cleavage stage embryos.

Figure 3 and Table 1 demonstrate the establishment of a significant difference in the rate of RNA synthesis between lobeless and normal embryos during the next 12 $\mathrm{hr}$ of development, from 6 to $18 \mathrm{hr}$ after trefoil. At the same time an increasing amount of gene activation is taking place, as shown by the increase in RNA synthesis per nucleus given in Table 2. This is the period at which the embryo enters into gastrulation. Gastrulation, however, is not as significant an event for this

TABLE 1

RNA Synthesis by Normal and Lobeless Embryos

\begin{tabular}{|c|c|c|c|}
\hline $\begin{array}{c}\text { Time after delobing } \\
(\mathrm{hr})\end{array}$ & $\begin{array}{c}\text { Number of } \\
\text { experiments }\end{array}$ & $\begin{array}{l}\text { Cold acid-soluble } \\
\text { uridine-H³ } \\
\text { ratio normal/lobeless }\end{array}$ & $\begin{array}{l}\text { Uridine incorporation } \\
\text { into RNA per embryo, } \\
\text { av. ratio normal//obeless }\end{array}$ \\
\hline 6 & 4 & 0.82 & 1.01 \\
\hline 18 & 3 & $\ldots$ & 1.18 \\
\hline 22 & 2 & & 1.16 \\
\hline 30 & 4 & 0.91 & 1.41 \\
\hline 48 & 2 & $\ldots$ & 1.75 \\
\hline 62 & 3 & $\cdots$ & 1.68 \\
\hline 72 & 2 & 0.86 & 1.95 \\
\hline
\end{tabular}

In each experiment matched lobeless and normal embryos were compared, in triplicate or quadruplicate determinations based on 15 or 20 embryos for each sample. Acid-soluble pool size decreased, from an absolute value at $6 \mathrm{hr}$ of about $3,300 \mathrm{cpm}$ per egg at the end of 2 -hr period of labeling, to an absolute value of about $1,100 \mathrm{cpm}$ per egg after $2 \mathrm{hr}$ of labeling at $72 \mathrm{hr}$. These two amounts of acid-soluble radioactivity represent about $150 \times$ the uridine- ${ }^{3}$ incorporated into RNA in $2 \mathrm{hr}$ by $72-\mathrm{hr}$ embryos. This, plus the fact that total acid-soluble radioactivity declines with age, while RNA synthesis becomes many times more active indicates that acid-soluble pool size is not a rate-limiting governor of RNA synthesis. The ratios active, indicates that acid-soluble pool size is not a rate-limiting governor of RNA synthesis. The ratios given for acid-soluble radioactivity in normal as opposed to lobeless embryos are corrected for the difference contains about $25 \%$ of the volume of the uncleaved egg or the trefoil stage.

TABLE 2

RNA Synthesis PER NuCleus

\begin{tabular}{|c|c|c|c|c|c|c|c|c|}
\hline \multirow{2}{*}{$\begin{array}{c}\text { Hours } \\
\text { post-trefoil }\end{array}$} & \multicolumn{2}{|c|}{$\begin{array}{l}\text { Number of Cells } \\
\text { per Embryo }\end{array}$} & \multicolumn{2}{|c|}{ Expt. I } & \multicolumn{2}{|c|}{-RNA, Av. Cpm/Cell } & \multicolumn{2}{|c|}{ Expt. III } \\
\hline & Lobeless & Normal & Lobeless & Normal & Lobeless & Normal & Lobeless & Normal \\
\hline $6-7$ & 15.4 & 12.2 & 0.61 & 1.05 & 2.0 & 3.0 & - & - \\
\hline 18 & 24.0 & 22.4 & 2.5 & 2.9 & 5.2 & 6.8 & 3.3 & 5.6 \\
\hline $30-31$ & 32.3 & 31.6 & 7.3 & 8.6 & 8.7 & 10.3 & 6.0 & 8.4 \\
\hline 38 & 62.8 & 63.2 & 5.6 & 6.3 & 4.7 & 6.6 & 5.1 & 7.1 \\
\hline $60-62$ & 126.0 & 125.8 & - & - & 3.9 & 5.2 & 5.9 & 7.3 \\
\hline
\end{tabular}

Cell counts were performed on 8-10 embryos at each time point. RNA synthesis per nucleus very likely varies according to which part of the cell cycle is assayed, and the values given in the right half of the table may not be median values. Nevertheless, the results are in accord with those of Fig. 3 , which shows that the greatest change in rate occurs between 18 and $30 \mathrm{hr}$. RNA synthesis rates used to calculate values for those time points in expts. I, II, and III above at which no direct measurements of RNA synthesis were made are estimated by interpolation between the measured points, as in Fig. 3 . 
embryo in terms of either morphogenesis or gene activity, as it is for an amphibian embryo. Differentiated tissues such as chordal mesoderm do not appear at this stage; nor in Ilyanassa does a major increase in nuclear activity coincide with the onset of gastrulation as it does in Xenopus, for example. A few hours later, however, such a major increase in gene activity is evident (Fig. 3). The rate of gene activity is highest (Table 2) after the completion of gastrulation at $30 \mathrm{hr}$. From this point on, lobeless and normal embryos show a 1.5- to 2 -fold difference in RNA synthetic activity. Yet the same number of cells is observed in lobeless as in normal embryos! Since the same number of genomes is present, the difference in RNA synthesis represents a difference in the level of gene activation in these genomes, a difference which becomes more clear-cut as the rate of gene activation increases in the period between 18 and $30 \mathrm{hr}$ after trefoil. After $30 \mathrm{hr}$ the rate of RNA synthesis per embryo continues to climb (Fig. 3). However, on a per-cell basis, the rate of RNA synthesis decreases slightly as more cells are formed (Table 2). Thus there is no further net gene activation and, as can be seen in Table 1, the difference in level of gene activity established during the activation phase remains essentially constant after $48 \mathrm{hr}$ post-trefoil.

Could the difference between lobeless and normal embryos be due to an "injury effect"?: Several facts argue against interpretation of these results as a nonspecific "injury effect," i.e., an interference with over-all RNA synthesis resulting from polar lobe removal: (a) Cell division, which is arrested by agents inhibiting RNA synthesis, DNA synthesis, protein synthesis, or energy metabolism, proceeds at a normal rate in lobeless embryos, since the latter have the same number of cells as normal embryos at any given time. It is unlikely on these grounds, that general injury, metabolic inhibition, or precursor starvation exists in lobeless embryos. (b) Lobeless embryos lack certain organs and tissues but other organs and tissues are constructed by lobeless embryos; the latter, furthermore, maintain the normal concentration of bulk RNA throughout the period of growth and differentiation between 4 and 8 days of development. ${ }^{21}$ Therefore the effect of lobe removal is specific only for certain areas of differentiation, and is not a general effect on all cell differentiation. (c) Wilson in $1904^{13}$ considered the argument that removal of a significant fraction of egg cytoplasm (thus of certrain organelles such as polar lobe mitochondria) might result in a general injury and thus affect the development of lobeless embryos. However, he was able to show that removal of comparable amounts of cytoplasm from other parts of the egg produced normal dwarf embryos rather than embryos similar to lobeless embryos. Furthermore, it can be noted that per unit amount of remaining cytoplasm, after delobing, the nuclei of lobeless embryos can be more active than those of normal embryos. This is clearly inconsistent with the hypothesis that insufficiency in some aspect of cytoplasmic metabolism supporting nuclear RNA synthesis can explain the effects of delobing. It is particularly clear in the initial $9-10 \mathrm{hr}$ of development, when lobeless and normal embryos show identical rates of RNA synthesis, that all metabolic systems required for RNA synthesis function equally well in lobeless and in normal embryos. Furthermore, both lobeless and normal embryos respond at the proper time and simultaneously undergo a striking activation of RNA synthesis, compared to their earlier rates of synthesis (Fig. 3 and Table 2). (d) Figure 4 shows sections of normal and lobeless embryos $32 \mathrm{hr}$ after delobing. All nuclei in both sections are active in RNA 


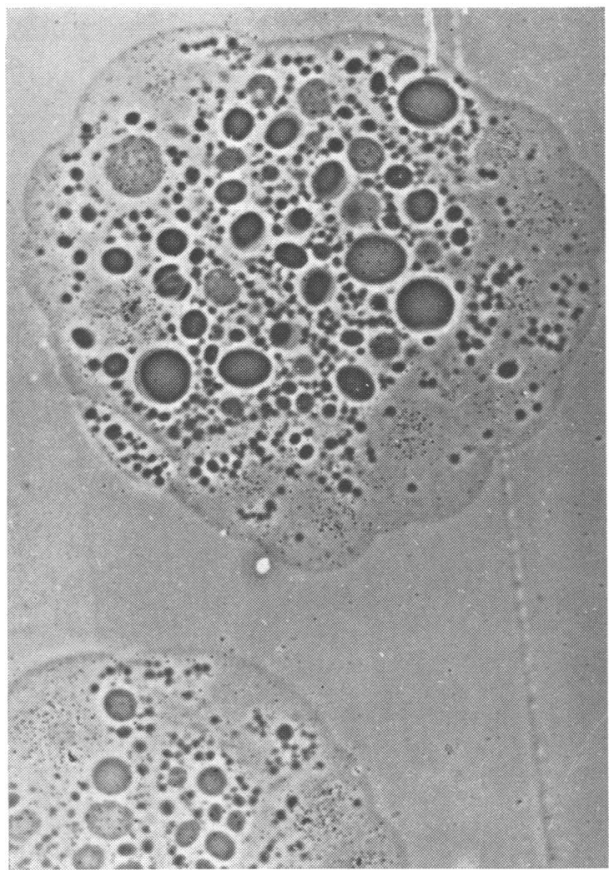

(a)

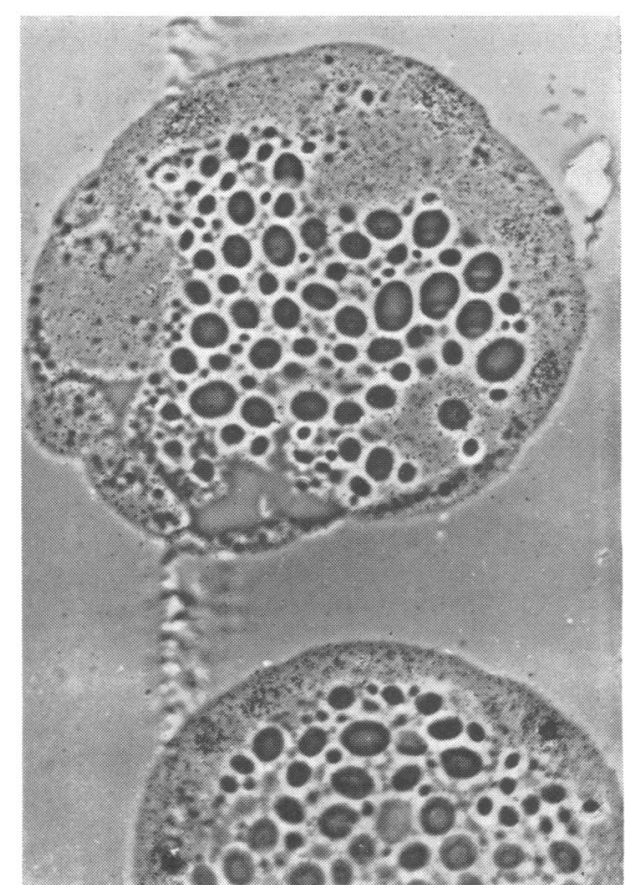

(b)

Fig. 4.--Comparison of RNA synthesis in lobeless $(a)$ and normal (b) 32-hr embryos. Note that all visible nuclei in both classes of embryo are labeled. Label appearing over the yolk platelets is probably not RNA synthesis since it is insensitive to actinomycin inhibition, in contrast to nuclear RNA synthesis, and furthermore the yolk platelet label can be removed by pretreatment with cold $0.20 \mathrm{~N}$ PCA. The PCA treatment, however, causes deterioration in the quality of the sections, and was therefore avoided when possible. Visible yolk platelets do not disappear until long after the phase of embryogenesis studied here. Furthermore, lobeless embryos contain much yolk, despite the loss of some yolk originally localized in the polar lobe. Removal of large amounts of yolk by extirpation of cytoplasm! from the egg in a different plane than that equivalent to lobe removal does not produce the qualitative effects of delobing. ${ }^{13}$ For these three reasons yolk starvation is not a feasible explanation for the difference between lobeless and normal embryos.

synthesis. It seems clear from such studies that delobing does not result in injury to any of the nuclei of the lobeless embryo.

Discussion.-While it is difficult to exclude with absolute certainty all other alternatives, the evidence we have presented points most directly to a delayed effect of polar lobe cytoplasm on gene action in the postgastrular Ilyanassa embryo. This effect becomes most apparent as the rate of gene activation increases. Since selective gene activation must underlie the onset of differentiation in the equivalent genomes of the embryonic cells, and since removal of the polar lobe is known to inhibit some, but not all, of the normally occurring differentiations, we might expect $a$ priori that polar lobe removal would interfere with selective gene activation. Our results are consistent with this expectation. It is interesting to note that Collier ${ }^{28}$ has reported that lobeless embryos synthesize less protein than do normal embryos, even during the early period when, according to our studies, the difference in RNA synthesis between lobeless and normal embryos is being established. Thus the absence of some RNA synthesis in lobeless embryos has an immediate effect. High immediacy of gene control ${ }^{29}$ is indeed expected to be associated with 
this phase of development, in contrast to the earlier phases. This is the phase preceding the onset of visible differentiation and is analogous in other organisms to the point at which embryos treated with actinomycin, or lethal hybrids, tend to arrest. During the time period with which we are here concerned, ribosomal RNA synthesis probably constitutes a minor or negligible fraction of the observed RNA synthesis, since Collier ${ }^{30}$ has demonstrated that bulk RNA content does not begin to increase until the fourth day of development.

Localization in egg cytoplasm of factors later to be involved with selective gene activation appears to be an extremely general phenomenon. Thus determinant-like morphogenetic factors have been demonstrated to exist in the egg cytoplasm of annelids, ${ }^{31}$ amphibia, ${ }^{32},{ }^{33}$ ascidians, ${ }^{34}$ insects, ${ }^{3,}{ }^{35}$ echinoderms, ${ }^{11}$ and in many other groups of animals, ${ }^{12}$ as well as in the molluscan forms. The elucidation of the mechanism by which prelocalized cytoplasmic factors affect the activity of embryonic nuclei such as those studied here would constitute an explanation for the initiation of differentiation in early development.

Summary.-Embryos of the snail Ilyanassa obsoleta were used to study the effect on later RNA synthesis of materials formed during oögenesis and localized in the egg cytoplasm by the time of first cleavage. It was found that removal of a distinct region of egg cytoplasm, the "polar lobe," depresses gene activation many hours later. These results, when combined with classical studies showing the presence of morphogenetic determinants in egg cytoplasm, suggest that gene activation in early embryogenesis may be mediated by cytoplasmically localized materials, thus accounting for initial nuclear differentiation.

We are indebted to Dr. Jack Collier for his invaluable advice and assistance.

* This research was supported in part by the American Cancer Society (grant E-334) and by the U.S. Public Health Service (grant GM 04919).

${ }^{1}$ Driesch, H., Anat. Anz. 7, 584 (1892).

${ }^{2}$ Gurdon, J. B., J. Embryol. Exptl. Morphol., 8, 505 (1960).

${ }^{3}$ Hegner, R. W., J. Morphol., 25, 376 (1914).

${ }^{4}$ Boveri, T., Arch. Zellforsch., 4, 132 (1910).

5 Morgan, T. H., Anat. Anz., 9, 141 (1894).

6 Other references collected in Morgan, T. H., Experimental Embryology (New York: Columbia University Press, 1927), chap. 21.

${ }^{7}$ Conklin, E. G., Woods Hole Biol. Lectures (1896).

${ }^{8}$ Wilson, E. B., Arch. Entwicklungsmech., 3, 19 (1896).

${ }^{9}$ Relevant papers of Boveri reviewed in Morgan, T. H., Experimental Embryology (New York: Columbia University Press, 1927), chap. 15.

${ }^{10}$ Driesch, H., Analytische Theorie der Organischen Entwicklung (Leipzig, 1894).

${ }^{11}$ Driesch, H., Arch. Entwicklungsmech., 7, 69 (1898).

${ }^{12}$ Wilson, E. B., The Cell (New York: Macmillan Co., 1925), 3rd ed., chap. 14.

${ }^{13}$ Wilson, E. B., J. Exptl. Zool., 1, 1 (1904).

${ }^{14}$ Ibid., p. 197.

${ }^{15}$ Crampton, E. G., Arch. Entwicklungsmech., 3, 1 (1896).

${ }^{16}$ Conklin, E. G., J. Morphol., 13, 1 (1897).

${ }^{17}$ Lacaze-Duthiers, H., Ann. Sci. Nat., 4, Ser. VI, 197 (1857).

${ }^{18}$ Clement, A. C., J. Exptl. Zool., 121, 593 (1952).

${ }^{19}$ Ibid., 132, 427 (1956).

${ }^{20}$ Ibid., 149, 193 (1962).

${ }^{21}$ Collier, J. R., personal communication (1964); Collier, J. R., in preparation (1965).

22 Collier, J. R., Embryologia, 3, 243 (1957). 
${ }^{23}$ Collier, J. R., Exptl. Cell Res., 21, 126 (1960).

${ }^{24}$ Gross, P. R., and G. H. Cousineau, Exptl. Cell Res., 33, 368 (1964).

${ }^{25}$ Denis, H., Develop. Biol., 9, 450 (1964).

${ }^{26}$ Brachet, J., and H. Denis, Nature, 198, 205 (1963).

${ }^{27}$ Harvey, E. B., Biol. Bull., 79, 166 (1940).

${ }^{28}$ Collier, J. R., Acta Embryol. Morphol. Exptl., 4, 70 (1961).

${ }^{29}$ Davidson, E. H., V. G. Allfrey, and A. E. Mirsky, these Proceedings, 49, 53 (1963).

${ }^{30}$ Collier, J. R., Exptl. Cell Res., 24, 320 (1961).

${ }^{31}$ Novikoff, A. B., Biol. Bull., 74, 211 (1938).

${ }^{32}$ Curtis, A. S. G., J. Embryol. Exptl. Morphol., 10, 410 (1962).

${ }^{33}$ Fankhauser, G., Ann. N.Y. Acad. Sci., 49, 684 (1948).

${ }^{34}$ Conklin, E. G., J. Acad. Nat. Sci. Phila., 2nd ser., 13, 1 (1905).

${ }^{35}$ Huettner, A. F., J. Morphol., 37, 385 (1923).

\title{
CATABOLIC REPRESSION OF BACTERIAL SPORULATION
}

\author{
By Pierre Schaeffer, Jacqueline Millet, and Jean-Paul Aubert \\ INSTITUT PASTEUR, PARIS \\ Communicated by André Lwoff, June 24, 1965
}

The formation of endospores in bacteria is generally studied in media which do not support growth: the exhausted growth medium or a solution of mineral salts into which washed growing bacteria are transferred.1,2 Under carefully adjusted cultural conditions, a reasonably synchronous sporulation can thus be obtained in the majority of the population. There seems therefore to be no need, and even no possibility, for a change in the conventional methods used to study sporulation.

An entirely new approach became available in 1961, however, when it was observed that spores are constantly being formed in cultures of Bacillus megaterium growing exponentially in a mineral-glucose medium. ${ }^{3}$ Similar results have recently been obtained with $B$. subtilis. ${ }^{4}$ Relative to the total viable population, the number of spores first reaches a limit value, and then increases with time at a constant rate, equal to the growth rate of the total population. ${ }^{3}$

The present work investigates the influence of various factors on the size of the sporulated fraction (hereafter called $\rho$ ) in growing cultures of $B$. subtilis. The interpretation of the results is that the probability for a cell in a growth medium to become committed to sporulate ${ }^{1,5}$ must be determined by the intracellular concentration of at least one nitrogen-containing catabolite repressing, directly or indirectly, the expression of all the sporulation genes. A preliminary account of this work has been included in recent reviews $;{ }^{6}, 7$ further evidence supporting the proposed interpretation will be published elsewhere. ${ }^{8,9}$

Experimental Procedure.-The wild Marburg strain of Bacillus subtilis has been used. A common mineral base for all media was prepared from the following three solutions (all figures in gm/liter); solution I: $\mathrm{K}_{2} \mathrm{HPO}_{4}, 10.5 ; \mathrm{KH}_{2} \mathrm{PO}_{4}, 3.5 ;$ solution II: $\mathrm{MgSO}_{4}, 7 \mathrm{H}_{2} \mathrm{O}, 5.0 ; \quad \mathrm{FeSO}$, $7 \mathrm{H}_{2} \mathrm{O}, 0.5$; solution III: $\mathrm{CaCl}_{2}, 5.0 ; \mathrm{MnCl}_{2}, 4 \mathrm{H}_{2} \mathrm{O}, 0.5$; solutions I and III were autoclaved, solution II sterile-filtered. The base medium is made of $100 \mathrm{vol}$ of solution I for 1 vol each of solutions II and III. Various substances are then added as carbon or as nitrogen source; the complete medium is thus fully described with the mention of the nature of each source, followed, in $\mathrm{gm} / \mathrm{liter}$, by its concentration [e.g., $\mathrm{NH}_{4} \mathrm{Cl}(0.5)$-glucose $\left.(2)\right]$. 